\title{
Self-Efficacy dan Kemampuan Pemecahan Masalah Siswa Kelas X SMA
}

\author{
Fiqi Naritio Agumuharram ${ }^{1}$, Slamet Soro ${ }^{2}$ \\ ${ }^{1,2}$ Program Studi Pendidikan Matematika, Fakultas Ilmu Pendidikan, Universitas Muhammadiyah Prof. Dr. HAMKA, \\ Jl. Tanah Merdeka No 20, Jakarta Timur, Indonesia \\ fnaritio17@gmail.com
}

\begin{abstract}
This study aims to determine and analyze the relationship between self-efficacy and problem-solving abilities of high school students. This research is a quantitative research with correlational method. The population in the study were students of SMAN 88 Jakarta Timur for the academic year 2020/2021. The research sample was 54 students who were randomly selected from $10^{\text {th }}$ grade. Data collection using two instruments, namely questionnaire instruments and test instruments. The questionnaire instrument was used to obtain data on students' self-efficacy and test instrument was used to obtain data on students' problem-solving abilities. The questionnaire instrument contains 33 statements about mathematical self-efficacy with 21 positive items and 12 negative items. The test instrument contains eight descriptive questions about solving mathematical problems. The results of data analysis show that selfefficacy and problem-solving ability have a significant correlation with the regression equation $\hat{\mathrm{Y}}=55,575+0,223 \mathrm{X}$ which means that the correlation is positive, and it is known that the level of closeness is included in the medium classification which is not weak and not strong. For further researchers, in order to examine other affective aspects with problem solving abilities, in order to find out whether there is a relationship or not.
\end{abstract}

Keywords: Self-Efficacy, Mathematical Problem-Solving Ability, correlation.

\begin{abstract}
Abstrak
Penelitian ini bertujuan untuk mengetahui dan menganalisis hubungan antara self-efficacy dengan kemampuan pemecahan masalah siswa SMA. Jenis penelitian merupakan penelitian kuantitatif dengan metode korelasional. Populasi dalam penelitian adalah siswa SMAN 88 Jakarta Timur tahun ajaran 2020/2021. Sampel penelitian adalah 54 siswa yang dipilih secara acak dari kelas X. Proses pengumpulan data menggunakan 2 macam instrumen yaitu instrumen angket dan instrumen tes. Data self-efficacy siswa diperoleh menggunakan instrumen lembar angket dan data kemampuan pemecahaan masalah siswa diperoleh menggunakan instrumen tes. Instrumen angket berisikan 33 pernyataan mengenai self-efficacy matematis dengan 21 butir positif dan 12 butir negatif. Instrumen tes berisikan delapan soal uraian mengenai pemecahan masalah matematis. Hasil analisis data menunjukan bahwa self-efficacy dan kemampuan pemecahan masalah memiliki hubungan signifikan dengan persamaan regresi $\hat{Y}=55,575+0,223 X$ yang berarti bahwa hubungan yang positif, serta diketahui tingkat keeratannya masuk kedalam klasifikasi sedang dimana tidak lemah dan juga tidak kuat. Bagi peneliti selanjutnya, agar meneliti aspek afektif lainnya dengan kemampuan pemecahan masalah, agar dapat mengetahui apakah terdapat hubungan atau tidak.
\end{abstract}

Kata kunci: Kemampuan Pemecahan Masalah Matematis, Self-Efficacy, hubungan

Copyright (c) 2021 Fiqi Naritio Agumuharram, Slamet Soro

$\square$ Corresponding author: Fiqi Naritio Agumuharram

Email Address: fnaritio17@gmail.com (Jl. Tanah Merdeka No 20, Jakarta Timur, Indonesia)

Received 12 July 2021, Accepted 21 July 2021, Published 05 August 2021

\section{PENDAHULUAN}

Matematika disebut sebagai ilmu universal yang menjadi dasar dalam perkembangan teknologi terbaru karena memiliki peranan sangat penting pada beraneka macam disiplin ilmu serta dapat memajukan daya pikir manusia. Karena itulah matematika dijadikan salah satu mata pelajaran yang harus dipelajari semua siswa pada setiap jenjang pendidikan. Pelajaran matematika memiliki tujuan agar siswa dapat memiliki kemampuan dalam pemahaman konsep, bernalar, memecahkan permasalahan, dan mengkomunikasikan gagasan serta dapat menerapkannya di kehidupan nyata. Tujuan belajar matematika tersebut juga selaras dengan yang apa dijabarkan oleh National Council of Teacher of Mathematics (Muhammad Daut Siagian, 2012) dimana proses pembelajaran matematika harus meningkatkan lima 
macam kemampuan, yaitu penalaran matematis, koneksi matematis, komunikasi matematis, representasi matematis serta pemecahan masalah matematis.

Salah satu kemampuan dalam mempelajari matematika yang penting dimiliki adalah pemecahan masalah. Pendapat dari Branca (Ulvah \& Afriansyah, 2016) mengatakan pemecahan masalah merupaakan tujuan utama ketika mempelajari matematika, bahkan dapat dikatakan jantung dari mempelajari matematika adalah proses pemecahan masalah. Branca (Puadi, 2017) juga berpendapat bahwa pertingnya pemecahan masalah dikarenakan tiga hal yakni karena pemecahan masalah adalah tujuan utama dalam pengajaran matematika, proses utama dalam kurikulum matematika (mulai dari metode, prosedur, dan juga strategi), dan kemampuan awal yang perlu dimiliki dalam mempelajari matematika. Dalam memecahkan masalah terdapat empat proses yang disampaikan oleh Polya (Amam, 2017) yaitu: memahami permasalahan (understanding the problem). merencanakan penyelesaian (making a plan), pelaksanaan penyelesaian (solving the problem), dan pemeriksaan kembali (looking back).

Adanya kemampuan pemecahan masalah ini dapat menjadikan siswa lebih terampil ketika memilah informasi, menganalisisnya serta juga menelitinya. Selain itu, intelektual siswa akan mengalami peningkatan dikarenakan belajar melalui proses penemuan (Purba \& Sirait, 2017). Dari beberapa penejelasan tersebut dapat diketahui bahwa pemecahan masalah adalah aspek yang mempengaruhi keberhasilan peserta didik dalam mempelajari matematika. Namun, fakta yang didapat bahwa siswa masih mempunyai kemampuan pemecagan masalah yang relatif rendah (Putra dkk., 2018). Rendahnya pemecahan masalah ini terjadi karena siswa sering kali merasa dirinya tidak yakin akan keputusannya dalam mengerjakan permasalahan matematika. Sedangkan bagi peserta didik keyakinan dalam dirinya sangatlah penting untuk menghdapi berbagai macam tugas. Keyakinian diri ini disebut dengan self-efficacy.

Selain dalam aspek kognitif, terdapat aspek lainnya yang perlu diperhatikan dalam pembelajaran matematika yaitu aspek afektif siswa. Hal ini dikarenakan aspek kognitif dan aspek afektif memiliki keterikatan yang sangat kuat (Sugiman \& Aziz, 2015). Aspek afektif merupakan perasaan atau sikap siswa dalam belajar yang akan berpengaruh ketika membuat keputusan. Aspek afektif yang memiliki pengaruh penting dalam pembelajaran matematika salah satunya adalahh self-efficacy (Alminingtias et al., 2018).

Self-efficacy menurut Bandura dalam (Nur \& Risnawita, 2012) adalah keyakinan seseorang tentang kemampuan dirinya sendiri ketika melakukan tindakan atau tugas yang diperlukan untuk menggapai hasil tertentu. Santrock (Fitriani, 2017) menyatakan bahwa keyakinan dalam diri seseorang yang mampu menguasai situasi tertentu dan dapat menghasilkan dampak yang positif disebut dengan self-efficacy. Pendapat lainnya oleh Maddux (Hendriana \& Kadarisma, 2019) yang mengatakan bahwa self-efficacy merupakan kehendak dalam diri seseorang untuk menentukan tindakan, upaya yang dikeluarkan, kegigihan dalam menghadapi permasalahan dan juga pengalaman emosional atau afektif. Bandura (Subaidi, 2016) juga mengatakan bahwa self-efficacy dalam diri seseorang dapat dipengaruhi oleh empat macam faktor, yakni: pengalaman keberhasilannya, pengalaman dari orang lain, persuasi verbal dan keadaan fisik orang tersebut. Maka dari berbagai macam pernyataan dapat dibuat kesimpulan bahwa secara umun self-efficacy adalah keyakinan dalam diri seseorang mengenai kemampuan dirinya sendiri ketika menghadapi situasi- 
situasi untuk mencapai tujuan tertentu didalam hidupnya. Oleh karena itu, apabila siswa memiliki selfefficacy yang kuat berarti merasa sanggup untuk dapat mengerjakan berbagai macam tugas, tak terkecuali dalam mengerjakan soal-soal matematika. Hal tersebut sejalan dengan Paul R.P dan Dale H.S (Sunaryo, 2017) yaitu bahwa siswa yang mempunyai self-efficacy rendah kurang mampu dalam memahami berbagai macam materi dalam matematika dan juga kemampuan membacanya dibandingkan siswa dengan selfefficacy tinggi.

Berdasarkan dari uraian yang sudah dijelaskan dapat diketahui, self-efficacy dan kemampuan pemecahan masalah adalah dua aspek yang mempengaruhi keberhasilan dalam pembelajaran matematika. Oleh karena itu, penulis memiliki ketertarikan untuk mencari tahu hubungan dari self-efficacy dan kemampuan pemecahan masalah siswa kelas 10 SMA. Sehingga, penelitian ini difokuskan untuk mengetahui hubungan antara self-efficacy siswa dengan kemampuan pemecahan masalah matematis siswa yang menggunakan metode penelitian korelasional. Maka, didapatkan rumusan masalah dalam penelitian ini yaitu: Apakah terdapat hubungan antara self-efficacy dan kemampuan pemecahan masalah matematis? Serta bagaimanakah tingkat huubungan yang diperoleh anatara kedua variabel tersebut.

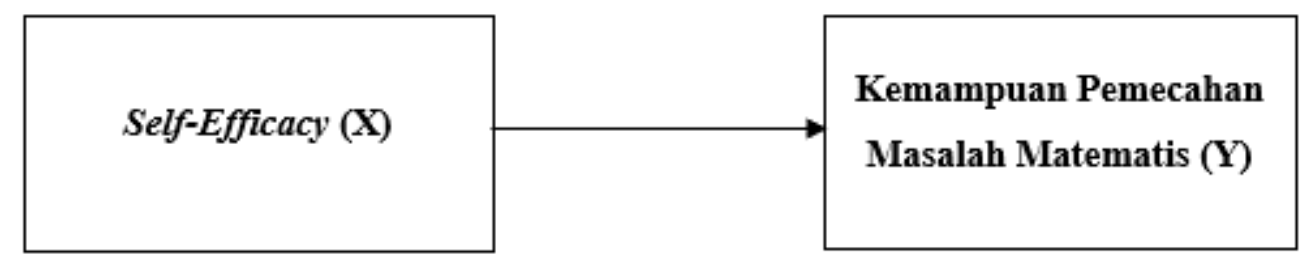

Gambar 1. Kerangka Konseptual

\section{METODE}

Pendekatan peneltian menggunakan pendekatan kuantitatif. Adapun metode yang diterapakan adalah metode korelasional. Terdapat dua variabel pada peneltian ini yaitu variabel terikat dan variabel bebas. Didalam studi ini tidak diberikan perlakuan baik untuk variabel bebas maupun terikatnya. Kemampuan pemecahan masalah siswa disini akan menjadi variabel terikat sedangkan self-efficacy akan menjadi variabel bebasnya. Sampel yang dipilih sebannyak 54 siswa dari 2 kelas sepuluh MIPA. Sampel dipilih dengan menggunakan teknik cluster random sampling dari keseluruhan siswa kelas sepuluh SMAN 88 Jakarta Timur. Sekolah ini dipilih karena visi dari sekolah ini adalah mewujudkan peserta didik yang berkarakter.

Proses pengambilan data dengan dua mcam instrumen yaitu lembar angket dan tes. Penggunaan instrumen angket untuk mencari tahu rasa self-efficacy siswa. Sedangkan untuk melihat kemampuan pemecahan masalah siswa menggunakan instrumen tes. Materi yang dipakai dalam instrumen tes adalah trigonometri pada semester genap, alasan dipilihnya materi ini dikarenakan ketika penelitian dilakukan materi ini telah dipelajari sampai sub materi implementasinya dalam kehidupann nyata. Lembar instrumen diberikan kepada siswa dalam bentuk google form baik angket maupun tes, alasan penggunaan google form dikarenakan saat ini sedang dilakukan pembelajaran daring. Tes pemecahan masalah yang diberikan 
berisikan 8 butir soal uraian dengan indikator memahami masalah, merencanakan pemecahan, melaksanakan rencana dan memeriksa kembali. Sedangkan untuk lembar angket berisikan 33 butir pernyataan dimana terdapat 21 pernyataan positif dan 12 penyataan negatif, dengan indikator yang digunakai sebagai berikut:

Tabel 1. Indikator angket self-efficacy

\begin{tabular}{|c|c|c|c|c|c|c|}
\hline \multirow{2}{*}{ Indicator } & \multirow{2}{*}{ Penyataan } & \multicolumn{5}{|c|}{ Respon } \\
\hline & & STS & TS & $\mathbf{N}$ & $\mathbf{S}$ & SS \\
\hline $\begin{array}{llr}\text { a. } & \begin{array}{l}\text { Keyakinan } \\
\text { kemampuan }\end{array} & \text { akan } \\
& \text { dalam } \\
\text { pemahaman } & \text { materi } \\
\text { matematika. } & \end{array}$ & $\begin{array}{l}\text { 1. Saya yakin mampu memahami } \\
\text { materi matematika dengan baik. }\end{array}$ & & & & & \\
\hline $\begin{array}{llr}\text { b. } & \text { Keyakinan akan } \\
& \text { kemampuan dalam } \\
& \text { mengerjakan tugas } \\
& \text { tentang matematika }\end{array}$ & $\begin{array}{l}\text { 2. Saya yakin dapat mengerjakan soal } \\
\text { matematika meskipun diluar } \\
\text { kemampuan saya. }\end{array}$ & & & & & \\
\hline $\begin{array}{l}\text { Keyakinan } r \text { akan } \\
\text { ketahanan dan keuletan } \\
\text { dalam pembelajaran } \\
\text { matematika. }\end{array}$ & $\begin{array}{l}\text { 3. Ketika menghadapui soal-soal } \\
\text { matematika yang menantang, } \\
\text { sayapun akan berusah lebih keras } \\
\text { dalam menyelesaikannya. }\end{array}$ & & & & & \\
\hline $\begin{array}{ll}\text { d. } & \text { Keyakinan berhasil } \\
\text { mencapai tujuan dalam } \\
\text { pembelajaran } \\
\text { matematika. }\end{array}$ & $\begin{array}{l}\text { 4. Saya yakin dengan berusaha dalam } \\
\text { pelajaran matematika, saya akan } \\
\text { mencapai hasil yang sesuai dengan } \\
\text { target. }\end{array}$ & & & & & \\
\hline
\end{tabular}

Instrumen yang diberikan kepada responden sudah dilakukan terlebih dahulu uji validitas dan uji reliabilitas sebelumnya. Pengujian dilakukan pada subjek uji coba sebanyak 30 responden. Hasil pengujian validitas untuk instrumen angket didapat 33 butir pernyataan valid dari 50 pernyataan dan untuk instrumen tes didapat 8 butir soal valid dari 10 soal. Hasil pengujian reliabilitas dari kedua variabel dinyatakan reliabel dengan klasisfikasi yang sangat tinggi. Selanjutnya, untuk pengujian analisis data dalam peneltian ini digunakan uji regresi linier sederhana. Namun, sebagai prasyarat pengujian akan dilakukan uji normalitas dan jugs uji linearitas terlebih dahulu.

\section{HASIL DAN DISKUSI}

\section{Deskripsi Data}

Data hasil tes instrumen kemampuan pemecahan masalah yang berasal dari 54 sampel, mendapatkan skor skor terendah sebesar 57 dan tertinggi sebesar 94. Hasil dari perhitungan didapatkan nilai mean 81,85; median 82; modus 77 dan standar deviasi 7,043. Berikut pada tabel 2 disajikan hasil deskripsi data berupa tabel frekuensi: 
Tabel 2. Tabel Frekuensi tes pemecahan masalah

\begin{tabular}{|c|c|c|c|c|}
\hline $\begin{array}{c}\text { Interval } \\
\text { Kelas }\end{array}$ & $\begin{array}{c}\text { Frekuensi } \\
\text { Absolut }\end{array}$ & $\begin{array}{c}\text { Frekuensi } \\
\text { Relatif (\%) }\end{array}$ & $\begin{array}{c}\text { F. Komulatif } \\
\text { Absolut }\end{array}$ & $\begin{array}{c}\text { F. Komulatif } \\
\text { Relatif (\%) }\end{array}$ \\
\hline $57-62$ & 1 & $1,85 \%$ & 1 & 0,02 \\
\hline $63-68$ & 1 & $1,85 \%$ & 2 & 0,04 \\
\hline $69-74$ & 3 & $5,56 \%$ & 5 & 0,09 \\
\hline $75-80$ & 19 & $35,19 \%$ & 24 & 0,44 \\
\hline $81-86$ & 15 & $27,78 \%$ & 39 & 0,72 \\
\hline $87-92$ & 11 & $20,37 \%$ & 50 & 0,93 \\
\hline $93-98$ & 4 & $7,41 \%$ & 54 & 1 \\
\hline Jumlah & 54 & $100 \%$ & \multicolumn{4}{|l}{} \\
\hline
\end{tabular}

Data hasil angket self-efficacy yang berasal dari 54 sampel, mendapatkan skor terendah sebesar 87 dan skor tertinggi sebesar 160. Hasil dari perhitungan didapatkan nilai mean 117,78; median 117; modus 115 dan standar deviasi sebesar 12,855. Berikut pada tabel 2 disajikan hasil deskripsi data berupa tabel frekuensi:

Tabel 2. Tabel Frekuensi angket self-efficacy

\begin{tabular}{|l|c|c|c|c|}
\hline $\begin{array}{l}\text { Interval } \\
\text { Kelas }\end{array}$ & $\begin{array}{l}\text { Frekuensi } \\
\text { Absolut }\end{array}$ & $\begin{array}{l}\text { Frekuensi } \\
\text { Relatif (\%) }\end{array}$ & $\begin{array}{l}\text { F. Komulatif } \\
\text { Absolut }\end{array}$ & $\begin{array}{l}\text { F. Komulatif } \\
\text { Relatif (\%) }\end{array}$ \\
\hline $87-97$ & 2 & $3,70 \%$ & 2 & 0,04 \\
\hline $98-108$ & 10 & $18,52 \%$ & 12 & 0,22 \\
\hline $109-119$ & 19 & $35,19 \%$ & 31 & 0,57 \\
\hline $120-130$ & 15 & $27,78 \%$ & 46 & 0,85 \\
\hline $131-141$ & 6 & $11,11 \%$ & 52 & 0,96 \\
\hline $142-152$ & 1 & $1,85 \%$ & 53 & 0,98 \\
\hline $153-163$ & 1 & $1,85 \%$ & 54 & 1 \\
\hline Jumlah & 54 & $100 \%$ & & \\
\hline
\end{tabular}

Selanjutnya disajikan deskripsi data berupa histogram dari kedua varibel yaitu data hasil self-efficacy siswa dan begitu juga data pemecahan masalah siswa.

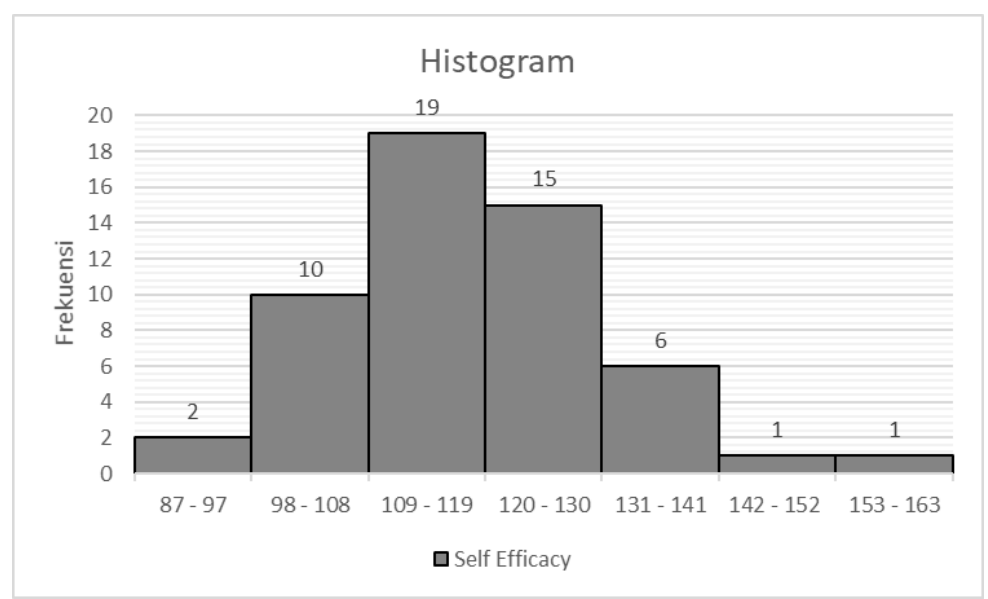

Gambar 2. Histogram variabel self-efficacy 


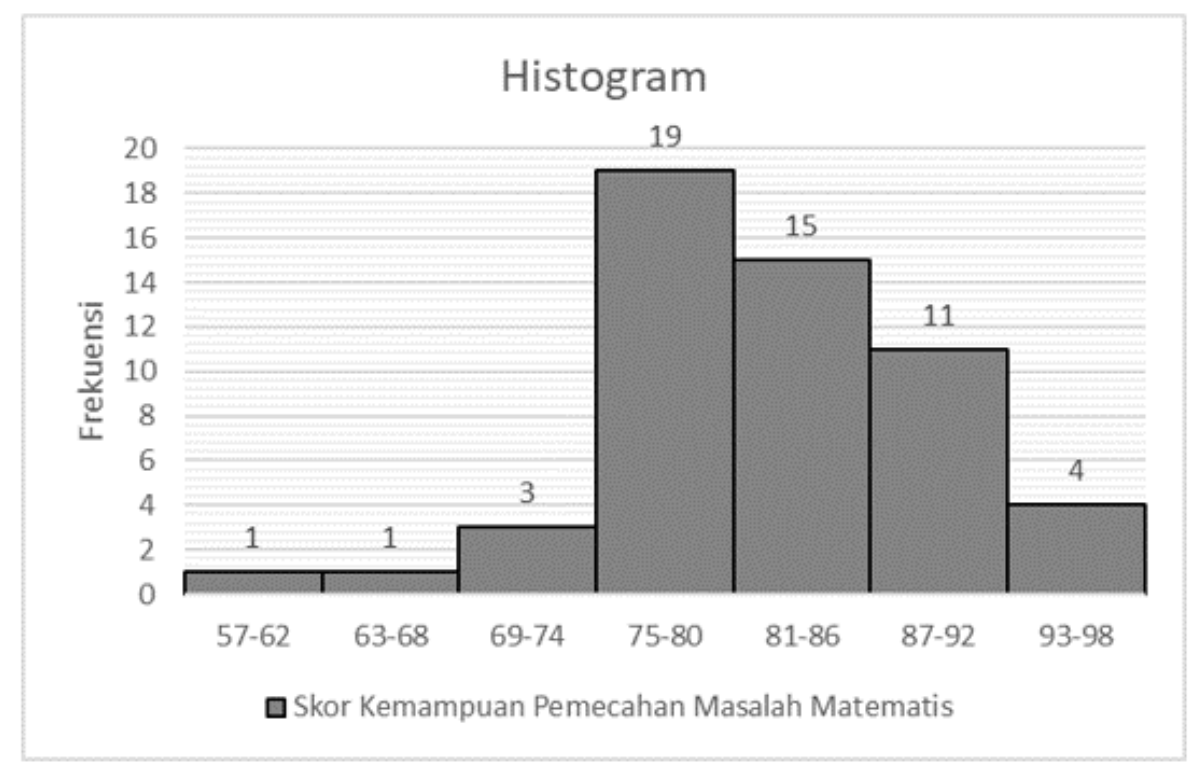

Gambar 3. Histogram pemecahan masalah

\section{Uji Persyaratan Analisis}

Sebelum dilakukan pengujian analisis data akan dilakukan terlebih dahulu pengujian prasyarat untuk kedua variabel. Karena analisis data berupa uji regresi linear sederhana, maka akan dilakukan uji normalitas dan uji linearitas. Pengujian normalitas data akan digunakan rumus Kolmogorov-Smirnov dengan hipotesis pengujian jika nilai signifikan > 0,05 maka data dapat dikatakan berdistribusi normal.

Tabel 3. Pengujian Normalitas Data

\begin{tabular}{|l|l|l|l|l|l|l|}
\hline \multicolumn{7}{|l|}{ Tests of Normality } \\
\hline & \multicolumn{2}{|l|}{ Kolmogorov-Smirnov ${ }^{\text {a }}$} & \multicolumn{3}{l|}{ Shapiro-Wilk } \\
\hline & Statistic & df & Sig. & Statistic & df & Sig. \\
\hline Self Efficacy & 0,080 & 54 & $.200^{*}$ & 0,976 & 54 & 0,346 \\
\hline $\begin{array}{l}\text { Kemampuan } \\
\text { Pemecahan } \\
\text { Masalah }\end{array}$ & 0,111 & 54 & 0,095 & 0,950 & 54 & 0,024 \\
\hline
\end{tabular}

Berdasarkan dari tabel 3 diatas diperoleh hasil nilai signifikan untuk data self-efficacy sebesar 0.200 dan data kemampuan pemecahan masalah sebesar 0.095. Maka, diketahui bahwa nilai signifikasn dari kedua data tersebut memiliki nilai yang lebih besar dari 0,05 maka dapat dibuat kesimpulan bahwa data kemampuan pemecahan masalah dan juga data self-efficacy merupakan data yang berdistribusi normal. Kemudian akan dilakukan pengujian linearitas dengan kriteria pengujian sebagai berikut:

Nilai Deviation from Linearty $>0,05$ maka data linear,

Nilai Deviation from Linearty $<0,05$ maka data tidak linear.

Berikut hasil uji linearitas dari data instrumen angket self-efficacy dan instrumen tes pemecahan masalah menggunakan metode ANOVA dengan aplikasi SPSS versi 26. 
Tabel 4. Hasil Lineariitas Variabel

\begin{tabular}{|c|c|c|c|c|c|c|c|}
\hline \multicolumn{8}{|c|}{ ANOVA Table } \\
\hline & & & $\begin{array}{l}\text { Sum of } \\
\text { Squares }\end{array}$ & df & $\begin{array}{l}\text { Mean } \\
\text { Square }\end{array}$ & $\mathbf{F}$ & Sig. \\
\hline \multirow{5}{*}{$\begin{array}{l}\text { Kemampuan } \\
\text { Pemecahan } \\
\text { Masalah * } \\
\text { Self Efficacy }\end{array}$} & $\begin{array}{l}\text { Between } \\
\text { Groups }\end{array}$ & (Combined) & 2079,948 & 34 & 61,175 & 2,118 & 0,043 \\
\hline & & Linearity & 435,990 & 1 & 435,990 & 15,093 & 0,001 \\
\hline & & $\begin{array}{l}\text { Deviation } \\
\text { from } \\
\text { Linearity }\end{array}$ & 1643,958 & 33 & 49,817 & 1,725 & 0,106 \\
\hline & $\begin{array}{l}\text { Within } \\
\text { Groups }\end{array}$ & & 548,867 & 19 & 28,888 & & \\
\hline & Total & & 2628,815 & 53 & & & \\
\hline
\end{tabular}

Berdasarkan dari tabel 4 diatas maka dapat diketahui nilai dari Deviation from Linearty adalah 0,106, sehingga mempunyai arti bahwa nilai Deviation from Linearty $>0,05$. Oleh karena itu dapat dibuat kesimpulan bahwa data variable self-effcacy dengan data variabel kemampuan pemecahan masalah memiliki hubungan yang linear. Karena kedua data variabel berdistribusi normal serta menghasilkan hubungan linear maka sekarang dapat dilakukan uji regresi linear sederhana.

\section{Uji Analisis Data}

Setelah mengetahui bahwa uji prasyaratan telah dipenuhi maka sekarang dapat dilakukan uji regresi linear sederhana. Dalam mengindentifikasi ada atau tidaknya hubungan antar kedua variabel maka digunakn kriteria pengujian, apabila nilai signifikan yang didapatkan kurang dari 0,05 makakedua variabel memiliki hubungan yang signifikan. Berikut merupakan hasil uji regresi linear dengan aplikasi SPSS versi 26.

Tabel 5. Uji analisis data

\begin{tabular}{|c|c|c|c|c|c|c|}
\hline \multicolumn{7}{|c|}{ Coefficients $^{\mathrm{a}}$} \\
\hline \multirow{2}{*}{\multicolumn{2}{|c|}{ Model }} & \multicolumn{2}{|c|}{$\begin{array}{l}\text { Unstandardized } \\
\text { Coefficients }\end{array}$} & \multirow{2}{*}{$\begin{array}{l}\text { Standardized } \\
\text { Coefficients } \\
\text { Beta }\end{array}$} & \multirow{2}{*}{$\mathbf{t}$} & \multirow{2}{*}{ Sig. } \\
\hline & & \multirow{2}{*}{$\begin{array}{l}\text { B } \\
55,575 \\
\end{array}$} & \multirow{2}{*}{\begin{tabular}{|l|}
$\begin{array}{l}\text { Std. } \\
\text { Error }\end{array}$ \\
8,220 \\
\end{tabular}} & & & \\
\hline 1 & (Constant) & & & & 6,761 & 0,000 \\
\hline & $\begin{array}{l}\text { Self } \\
\text { Efficacy }\end{array}$ & 0,223 & 0,069 & 0,407 & 3,215 & 0,002 \\
\hline
\end{tabular}

Berdasarkan tabel 5 diatas dapat diketahui bahwa nilai signifikan yang didapat adalah 0,002 yang berarti bahwa nilai signifikannya $<0,05$. Sehingga, dapat ditarik kesimpulann bahwa terdapat hubungan antara self-efficacy dan kemampuan pemecahan masalah secara signifikan. Kemudian dalam menentukan bentuk persamaan regresi linearnya dapat diketahui dari nilai kolom B. Sehingga diperoleh nilai konstanta yaitu 55,575 dan koefisien regresi sebesar 0,223 maka dengan menggunakan rumus $\hat{Y}=a+b x$ dapat 
dibuat bentuk persamaan regeresi sebagai berikut: $\hat{Y}=55,575+0,223 X$. Karena nilai koefisien regeresi mempunyai nilai positif, maka dapat dikatakan bahwa self-efficacy memiliki hubungan yang postif dengan kemampuan pemecahan masalah matematis. Kemudian untuk mencari tahu seberapa erat timgkat hubungan self-efficacy dengan kemampuan pemecahan masalah dapat dilihat dari nilai koefisiennya. Sedangkan untuk mengetahui seberapa besar self-efficacy mempengaruhi kemampuan pemecahan masalah dapat dilihat dari nilai derteminan koefisien. Berikut disajikan hasil perhitungannya:

Tabel 6. Koefisien Korelasi dan Determinan Kofisien

\begin{tabular}{|l|l|l|l|l|}
\hline \multicolumn{3}{|l|}{ Model Summary } \\
\hline Model & R & R Square & $\begin{array}{l}\text { Adjusted } \\
\text { R Square }\end{array}$ & $\begin{array}{l}\text { Std. Error of } \\
\text { the Estimate }\end{array}$ \\
\hline 1 & $.407^{\text {a }}$ & 0,166 & 0,150 & 6,494 \\
\hline
\end{tabular}

Berdasarkan dari tabel 6 diatas didapatkan bahwa nilai koefisien korelasi adalah 0,407. Hasil tersebut memiliki arti yaitu dimana tingkat hubungan antara self-efficacy dan pemecahan masalah berada pada tingkat kategiori yang sedang. Sedangkan nilai dari deteminan koefisien yang diperoleh hanya sebesar 0,166 atau $16.6 \%$. Sehingga dapat dikatakan bahwa halnya self-efficacy hanya mempengaruhi kemampuan pemecahan masalah sebesar $16,6 \%$, sedangkan sisanya $83,4 \%$ oleh faktor lainnya

Bedasarkan hasil dari analisis perhitungan uji regresi linear sederhana diperoleh nilai signifikan sebesar 0,002. Hasil tersebut memiliki arti bahwa self-efficacy dan kemampuan pemecahan masalah terdapat hubungan yang signifikan. Hasil tersebut sejalan dengan penelitian yang dilakukan oleh Alifia \& Rakhmawati (2018) yaitu self-efficacy mempunyai peranan yang sangat penting dalam segala sesuatu, salah satunya bagi siswa yang sedang melakukan pemecahan masalah matematis. Begitu juga sejalan dengan hasil penelitian Jatisunda (2017) yaitu siswa yang memiliki self-efficacy yang tinggi maka pencapaian atau nilai kemampuan pemecahan masalah yang dimiliki akan ikut tinggi. Oleh sebab itu, haruslah ditanamkan rasa self-efficacy siswa selama proses pembelajaran oleh pengajar. Salah satu caranya dengan menciptakan suasana atau lingkungan belajar yang menyenangkan, menginspirasi dan menumbuhkan rasa percaya diri serta memotivasi peserta didik ketika proses pembelajaran, dengan hal tersebut dapat meningkatkan selfefficacy (Subaidi, 2016).

\section{KESIMPULAN}

Berdasarkan hasil penelitian yang sudah disampaikan, maka dapat dibuat kesimpulan bahwa: (1) Self-efficacy memiliki hubungan signifikan dengan kemampuan pemecahan masalah siswa di kelas 10 SMAN 88 Jakarta Timur, (2) Hasil dari hubungan antar kedua variabel merupakan hubungan positif yang memiliki arti jika siswa memiliki self-efficacy yang tinggi maka kemampuan pemecahan masalahnya akan 
tinggi pula begitu pun sebaliknya, (3) Tingkat keeratan hubungan antar variabel masuk dalam kategori yang sedang berarti tidak lemah namun juga tidak kuat.

\section{REFERENCE}

Alifia, N. N., \& Rakhmawati, I. A. (2018). Kajian Kemampuan Self-efficacy Matematis Siswa Dalam Pemecahan Masalah. Jurnal Elektronik Pembelajaran Matematika, 05(1), 44-54.

Alminingtias, F. M. N., Soro, S., \& Handayani, I. (2018). Hubungan Self-Efficacy dengan Hasil Belajar Matematika Siswa di MAN 7 Jakarta. Prosiding Seminar Nasional Pendiddikan Matematika UHAMKA, 01, 365-371. https://journal.uhamka.ac.id/index.php/senamku/article/view/2725

Amam, A. (2017). Penilaian Kemampuan Pemecahan Masalah Matematis Siswa Smp. Teorema, 2(1), 39. https://doi.org/10.25157/.v2i1.765

Hendriana, H., \& Kadarisma, G. (2019). Self-Efficacy dan Kemampuan Komunikasi Matematis Siswa $\begin{array}{lllll}\text { SMP. JNPM (Jurnal Nasional Pendidikan Matematika), } & 3(1), & 153 .\end{array}$ https://doi.org/10.33603/jnpm.v3i1.2033

Jatisunda, M. G. (2017). Hubungan Self-Efficacy Siswa SMP dengan Kemampuan Pemecahan Masalah Matematis. Jurnal THEOREMS (The Original Research of Mathematics), 1(2), 24-30.

Muhammad Daut Siagian. (2012). Model Pembelajaran Kooperatif Tipe Circ Dengan Pendekatan Konstruktivisme Untuk Meningkatkan Kemampuan Koneksi Matematik. Unnes Journal of Mathematics Education Research, 1(2), 58-67.

Nur, G., \& Risnawita, R. (2012). Teori-Teori Psikologi. Ar-Ruzz Media.

Puadi, E. F. W. (2017). Analisis Peningkatan Kemampuan Koneksi Matematis Mahasiswa Ptik Melalui Pembelajaran Berbasis Masalah. 5. http://jurnal.upmk.ac.id/index.php/jumlahku/article/view/139

Purba, O. N., \& Sirait, S. (2017). PENINGKATAN KEMAMPUAN PEMECAHAN MASALAH PADA MATERI TRIGONOMETRI DENGAN MODEL LAPS-Heuristic PADA KELAS X SMA SHAFIYYATUL AMALIYAH. II(1). https://doi.org/10.31227/osf.io/fhq3e

Putra, H. D., Thahiram, N. F., Ganiati, M., \& Nuryana, D. (2018). Kemampuan Pemecahan Masalah Matematis Siswa SMP pada Materi Bangun Ruang Development of Project-Based Blended Learning Model to Support Student Creativity in Designing Mathematics Learning in Elementary School. JIPM (Jurnal Ilmiah Pendidikan Matematika), 6(2), 82-90.

Subaidi, A. (2016). Self-Efficacy Siswa Dalam Pemecahan Masalah Matematika. Jurnal Eigma. Universitas Madura, 1(2), 64-68.

Sugiman, \& Aziz. (2015). Analisis Kesulitan Kognitif Dan Masalah Afektif Siswa Sma Dalam Belajar Matematika Menghadapi Ujian Nasional. Jurnal Riset Pendidikan Matematika, 2(2), 162-147. http://journal.uny.ac.id/index.php/jrpm/index

Sugiyono. (2017). Metode Penelitian Pendidikan Pendekatan Kuantitatif, Kualitatif, dan R\&D. Alfabeta.

Sunaryo, Y. (2017). PENGUKURAN SELF-EFFICACY SISWA DALAM PEMBELAJARAN MATEMATIKA DI MTs N 2 CIAMIS. Teorema, 1(2), 39. https://doi.org/10.25157/.v1i2.548 
Ulvah, S., \& Afriansyah, E. A. (2016). Kemampuan Pemecahan Masalah Matematis Siswa ditinjau melalui Model Pembelajaran SAVI dan Konvensional. Jurnal Riset Pendidikan, 2(2), 142-153. http://hikmahuniversity.ac.id/lppm/jurnal/2016/text07.pdf 